\title{
BMJ Open Doctors' professional identity and socialisation from medical students to staff doctors in Japan: narrative analysis in qualitative research from a family physician perspective
}

\author{
Junji Haruta (D) , ${ }^{1,2}$ Sachiko Ozone, ${ }^{3}$ Jun Hamano (D) ${ }^{4}$
}

To cite: Haruta J, Ozone S, Hamano J. Doctors' professional identity and socialisation from medical students to staff doctors in Japan: narrative analysis in qualitative research from a family physician perspective. BMJ Open 2020;10:e035300. doi:10.1136/ bmjopen-2019-035300

- Prepublication history for this paper is available online. To view these files, please visit the journal online (http://dx.doi. org/10.1136/bmjopen-2019035300).

Received 30 0ctober 2019 Revised 21 May 2020 Accepted 10 June 2020

Check for updates

(C) Author(s) (or their employer(s)) 2020. Re-use permitted under CC BY-NC. No commercial re-use. See rights and permissions. Published by BMJ.

For numbered affiliations see end of article.

Correspondence to

Dr Junji Haruta;

junharujp@keio.jp

\section{ABSTRACT}

Objective Becoming a doctor involves transforming a lay person into a medical professional, which is known as professional socialisation. However, few studies have clarified differences in the professional socialisation process in detail. The aim of this study was to clarify the process of professional socialisation of medical students to residents to staff doctors.

Design We used narrative analysis in qualitative research as a theoretical framework.

Setting This study was conducted in Japan.

Participants Participants were collected using a purposive sample of doctors with over 7 years of medical experience. We conducted semistructured interviews from September 2015 to December 2016, then used a structured approach to integrate the sequence of events into coherent configurations.

Results Participants were 13 males and 8 females with medical careers ranging from 8 to 30 years. All participants began to seriously consider their own career and embodied their ideal image of a doctor through clinical practice. As residents, the participants adapted as a member of the organisation of doctors. Subsequently, doctors exhibited four patterns: first, they smoothly transitioned from 'peripheral' to 'full' participation in the organisation; second, they could no longer participate peripherally but developed a professional image from individual social interactions; third, they were affected by outsiders' perspectives and gradually participated peripherally; fourth, they could not regard the hospital as a legitimate organisation and could not participate fully. Conclusion The professional socialisation process comprises an institutional theory, professional persona, legitimate peripheral participation and threshold concepts. These findings may be useful in supporting professional development.

\section{INTRODUCTION}

The process by which a medical student matures into a healthcare professional is known as socialisation. ${ }^{1}$ Professional socialisation is defined as the process of transforming a beginner into a professional. This process
Strengths and limitations of this study

- This study used narrative analysis to illustrate the trajectory of medical professional identity formation.

- Strengths include applying narrative analysis suitable for identifying the socialisation patterns of medical doctors in the continuity of their careers.

- Limitations include a small sample size of 21 Japanese participants, of whom many were family physicians and only a small number were specialists.

- Participants consisted of 13 males and 8 females with medical careers ranging from 8 to 30 years.

integrates work-based norms, values, beliefs, knowledge, skills and expected roles, and adapts the beginner to the culture of the experts. ${ }^{2}$ A medical professional's identity, constructed through medical professional socialisation, is defined as 'a representation of self, achieved in stages over time during which the characteristics, values, and norms of the medical profession are internalised, resulting in an individual thinking, acting and feeling like a physician'. ${ }^{3}$ That is, medical professional socialisation aims to develop a professional identity and adapt a person to the role of medical expert. ${ }^{4}$

In practice, the socialisation of doctors is affected by role models, clinical experience, ${ }^{5}$ the healthcare system and school or organisational environment, as well as by the attitudes of colleagues and supervisors towards patients. ${ }^{6}$ Additionally, most doctors adapt to the organisation by acquiring the necessary skills to carry out their duties. ${ }^{78}$ Doctors thereby become members of the organisation of a hospital, and are conscious of belonging to the community and of their responsibility as doctors. ${ }^{9}$ According to the concept of legitimate peripheral participation (LPP), medical students become incorporated into 
the community of doctors as members based on degree of participation and how participation and non-participation change over time. ${ }^{9}$

A doctor's professional socialisation and the development of their identity are some of the most important aspects of medical education. ${ }^{10-14}$ However, few studies have clarified the details of differences in the professional socialisation process, such as when and how doctors are influenced by organisations and the education system, and how their professional identity as a doctor is acquired. A formal outline of the process of socialisation might provide medical educators and programme directors with clues on how to prevent identity crises for doctors in training.

In particular, the specialty of family physician is more ambiguous than other specialties, and family physicians tend to struggle with their identity due to the overlap in the scope of their practice with that of general internal medicine, general paediatrics, psychiatry and obstetricsgynaecology. Family physicians are more interested in their identity and how others perceive them ${ }^{15}$ because they have difficulties with professional identity formation within mainstream biomedicine and with the counterculture movement internationally. ${ }^{16}{ }^{17}$ Thus, professional socialisation from a family physician perspective may better reveal details of how anguish and/or struggle with professional identity formation is manifested than the perspectives of other specialties.

Here, therefore, with a focus on evaluation from the perspective of family physicians, as distinct from the perspectives of other specialties, we aimed to clarify the process of professional socialisation of medical students to residents to staff doctors. In particular, the specific aim of this study was to examine how doctors perceive their acquired knowledge and values in the process of developing their professional identity as a doctor.

\section{METHODS}

\section{Theoretical framework}

We used narrative analysis, which is characterised as a group of methods used to interpret commonality among stories. ${ }^{18}$ Our present aim is consistent with that of narrative analysis because we examined the subjects' narrative as a whole rather than as decontextualised fragmented data. Narrative analysis inductively clarifies a typology of narratives, conceptually organises them into thematic categories, and then illustrates exemplar narratives or vignettes. ${ }^{18} 19$ Common thematic elements across a number of participants are used to develop a descriptive framework of professional socialisation. ${ }^{19}$ A number of other studies of the professional identity of medical professionals have also used narrative analysis. ${ }^{20}{ }^{21} \mathrm{We}$, therefore, adapted narrative analysis as a theoretical framework for the present study.

\section{Setting}

The setting was the Japanese medical education system (figure 1). Similarly to many other countries, eligibility to

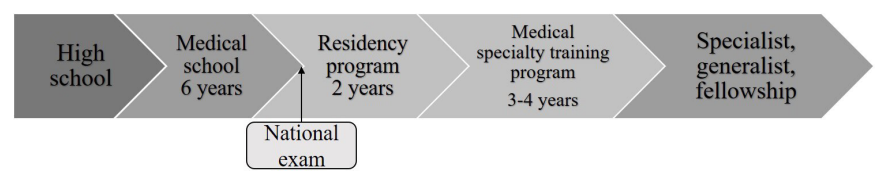

Figure 1 Medical education system in Japan.

enter medical school in Japan is assessed in high school graduates. The standard undergraduate medical education programme is 6 years. The Japanese national exam comprises only a single examination, in sixth grade. In 2004, the Council for Matching, a non-government organisation, implemented and organised a system to match graduating medical students to 2-year residency programmes in Japan. A nationwide matching system had not been previously available, and residents had to randomly apply to individual training programmes in which they were interested. After the initial 2 years of required postgraduate training in Japan, each trainee advances into his or her own career path. Some doctors enter graduate school, while others proceed to advanced clinical training courses as fellows, or move on to become family physicians in the community.

According to Organisation for Economic Co-operation and Development (OECD) data for 2017, the overall average number of doctors per 1000 people was 3.5, compared with 2.4 in Japan. ${ }^{22}$ In contrast, Japan has the greatest number of hospital beds among OECD countries and approximately 100000 clinics, of which more than $90 \%$ are private and less than $10 \%$ are public. ${ }^{23} 24$ Additionally, many doctors traditionally open primary care clinics after several years of organ-specific training at medical school or a large hospital. ${ }^{25}$ For family medicine, however, the number of Japanese doctors who have officially completed training as family physicians as of April, 2020 is only $732 .{ }^{26}$ Due to this wide dispersion of relatively few doctors in hospitals and the paucity of family physicians, some organ-specific doctors encounter opportunities to work in primary care settings, where relatively small numbers of doctors often struggle to provide care to large numbers of patients. ${ }^{25}$ For this reason, many physicians in universities work in clinics and/or outpatient departments in community hospitals once or twice a week. In contrast, family physicians who belong to a clinic generally work only in that clinic.

\section{Data collection: semistructured interview}

We conducted semistructured interviews from September 2015 to December 2016. Semistructured interviews are the primary method used for data collection in socialisation studies. ${ }^{15} 27$ We interviewed each participant for 90-120 $\mathrm{min}$ in a private room or quiet cafe, after obtaining consent from the interviewee. We developed a series of questions that would allow us to compare the contents and diversity of expertise, and demonstrate the relationship between the socialisation of doctors and acquisition of knowledge and values. The questions were: 'What kinds of things did you learn and how did you learn them when you were a medical student, junior resident, 
senior resident, and staff doctor?'; 'Did you make changes between being a medical student and your training? If so, what did you change and how did you make these changes?'; 'How did you feel about the image of the doctor you envisaged before entering the medical department, or becoming a medical student, junior resident, senior resident, and staff doctor? How did you select your professional career?'; and 'Please describe the events that influenced your learning while developing as a doctor.'

JHar, SO and JHam conducted pilot interviews on each other to standardise the interviewing technique and interview questions. In addition, we chose the most appropriate interviewer for each participant such that the combination of interviewee and interviewer would allow the interviewee to feel at ease and provide frank answers to questions, such as those inquiring about relationships between residents and teaching doctors in previous workplaces. Moreover, if the interviewers could not conduct in-person interviews due to logistical issues such as residential distance, the interviews were conducted using the online communication tool Skype. Skype-conducted pilot interviews were conducted, in which the influence of the interviewer with respect to matters like sound quality were verified.

\section{Patient and public involvement}

Patients and the public were not involved in the design or conduct of the study.

\section{Study participants}

To clarify the professional socialisation process of family physicians, who typically have a more diverse career than other specialists, we selected study participants using purpose sampling, in which we discussed multifaceted aspects of the participants' careers, such as facilities; location; career experience, including training organisation, university hospital, community hospital and clinic, and career changes; experience in academic research; and their cooperation with the interview. As much as possible, interviewers were paired with interviewees with whom they had not worked with for more than 1 year.

The inclusion criterion was a doctor with a medical career of 7 years or longer, on the basis that they would have sufficient experience to be able to look back and reflect on their training and career.

\section{Data analysis}

All interviews were recorded using a voice recorder and transcribed verbatim. The interview contents were analysed using the four steps of structural analysis proposed by Gregg $^{28}$ :

Step 1: Divide the text into episodes, which comprise the plot/sequence of the story.

Step 2: Eliminate material that is irrelevant to the plot (often facts).

Step 3: Identify the stanzas in each episode that contain an embedded story.
Step 4: Identify contrasts in binary oppositions and mediating terms (a blend of the shared features) within and across each episode.

The three authors analysed the entire narratives provided by the 21 participants and divided them into five sections: before medical school, medical student, junior resident, senior resident and staff doctor. JHar extracted relevant material from the interviews of eight participants, as did SO for six participants and JHam for seven participants. Subsequently, the three authors together checked whether the plots matched the contents that each author individually had divided into stages using the original data. In step 3, we identified the stanzas in which the participant's narrative was associated with professional socialisation. JHam, SO and JHar compared the series of stories on professional identity formation and clarified the themes based on the concept of professional socialisation. We ensured that the themes appeared as a consistent narrative pattern across each interview. We conducted periodic data analysis, and checked the steps performed by each author to ensure consistency in interpretation and appropriate sampling to improve the robustness of the analysis. ${ }^{19}$

All participants provided informed consent prior to participation. To protect privacy, interviewee quotes in this paper are identified by randomly assigned number codes rather than the participants' names.

\section{RESULTS}

\section{Demographic data of the participants}

The 21 participants included 16 Japan Primary Care Association-certified Family Physicians, of whom one had a subspecialty of cardiology; two had a subspecialty of palliative medicine and one was a $\mathrm{PhD}$ student in the UK. The remaining five consisted of two gastroenterologists, one brain surgeon, one obstetrician and gynaecologist, and one emergency and orthopaedic surgeon. Eight of the 21 participants were female, and all had clinical experience ranging from 8 to 30 years. The participants belonged to eight city hospitals, five clinics and seven universities, while one was a graduate student in the UK (table 1). By location, the participants worked in Ibaraki Prefecture, Tokyo, Hokkaido, Kanagawa, Kyoto, Okinawa and the UK.

\section{Overview of professional socialisation as a doctor}

We conducted in-person interviews with all participants except two, who were interviewed using Skype. We found that all doctors related to the common themes of 'Realisation as a Doctor' as medical students in clinical practice and 'Organisational Socialisation' as residents through the process of becoming a member of their attending hospital. Subsequently, we identified four distinct patterns of professional socialisation among the participants. These four patterns may represent the different ways individuals balance organisational socialisation according 
Table 1 Demographic data of study participants

\begin{tabular}{lllll} 
Code no & Gender & $\begin{array}{l}\text { Clinical experience } \\
\text { (years) }\end{array}$ & Specialty & Institution \\
\hline 1 & M & 12 & Family physician & Clinic \\
2 & F & 12 & Family physician & University \\
3 & M & 12 & Family physician & Clinic \\
4 & M & 14 & Family physician, palliative medicine & University \\
5 & M & 12 & Family physician & Hospital \\
6 & F & 12 & Family physician & PhD student \\
7 & M & 11 & Family physician & Clinic \\
8 & F & 11 & Family physician, Palliative medicine & Hospital \\
9 & F & 8 & Family physician & Hospital \\
10 & M & 13 & Family physician & Clinic \\
11 & M & 30 & Family physician, cardiologist & Hospital \\
12 & F & 16 & Family physician & University \\
13 & F & 12 & Family physician & Clinic \\
14 & M & 11 & Family physician & Hospital \\
15 & F & 9 & Family physician & Hospital \\
16 & M & 19 & Family physician & Hospital \\
17 & M & 13 & Emergency and orthopaedic surgery & University \\
18 & M & 14 & Obstetrics and gynaecology & Hospital \\
19 & M & 13 & Brain surgeon & University \\
20 & M & 22 & Gastroenterologist & University \\
21 & F & 21 & Gastroenterologist & University \\
\hline
\end{tabular}

F, female; M, male.

to their particular specialty area and self-learning style (table 2, figure 2).

Realisation as a doctor

Medical students began to compare their observations of doctors, healthcare professionals, the community and hospitals with their imagined concepts, and started to seriously consider doctors' tasks, attitudes and way of thinking during clinical practice. They contemplated their own career and whether they themselves aligned with their image of a doctor. When the two did not match, they explored and embodied their ideal image through the clinical experience of other doctors and patients (table 3).

\section{Organisational socialisation}

During their junior residency, which refers to a 2-year period of work experience following graduation as a doctor, all participants experienced organisational socialisation in hospitals as they conducted rotations across the medical departments. They had to carry out tasks as

Table 2 Four patterns of self-learning style and specialty area

\begin{tabular}{|c|c|c|c|}
\hline & When and what specialty area & Self-learning style & Organisational socialisation \\
\hline Pattern 3 & $\begin{array}{l}\text { Need role models and professional } \\
\text { belonging }\end{array}$ & \multicolumn{2}{|c|}{$\begin{array}{l}\text { Public persona and focus more on LPP in hospital than } \\
\text { individual learning style }\end{array}$} \\
\hline Pattern 4 & \multicolumn{3}{|c|}{$\begin{array}{l}\text { Hesitate to conduct LPP, then explore professional belonging and professional identity as a doctor in an } \\
\text { organisation }\end{array}$} \\
\hline
\end{tabular}

LPP, legitimate peripheral participation. 


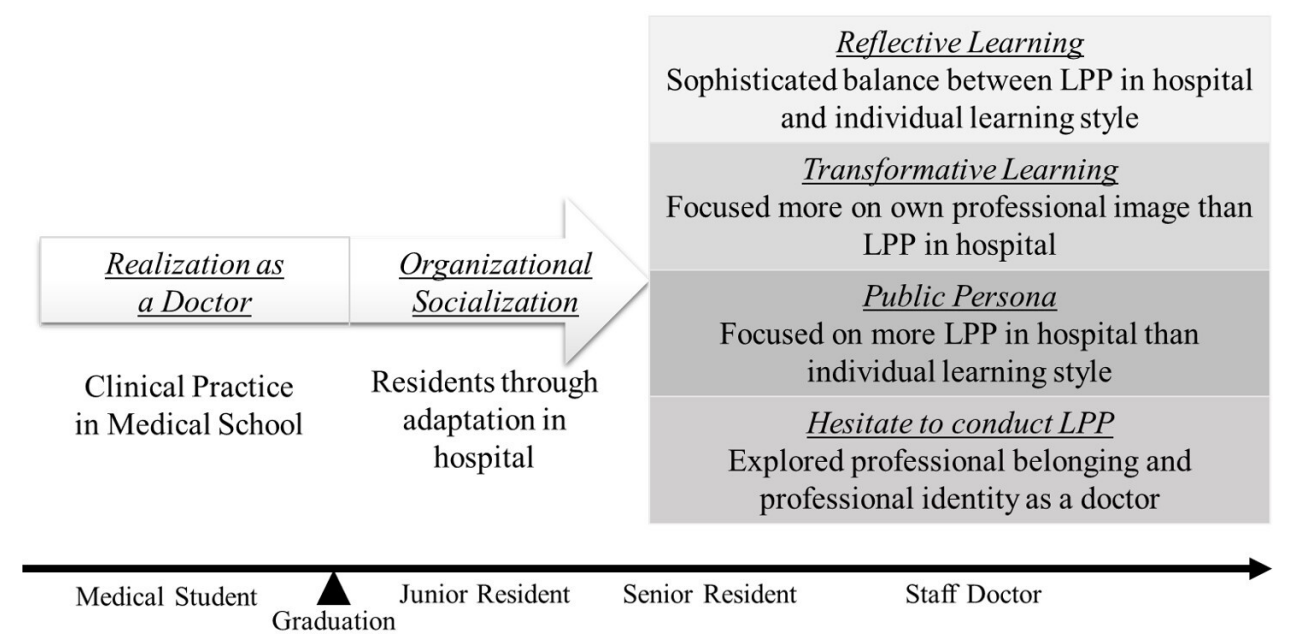

Figure 2 Professional socialisation as a doctor. LPP, legitimate peripheral participation.

instructed by their supervisors and in this way learnt their role as doctors in the hospital.

In addition, doctors valued their colleagues as an inner group, as doctors with whom they felt a kinship and friendship because of what they had been through together as residents. Some compared their own ability, motivation, and enjoyment of work with that of their colleagues. In contrast, some felt emotional undulations such as depressive moods because they regarded colleagues as rivals, with envy, as markers of their own success or failure and as competitors.

They strengthened their mutual connections with colleagues in their inner group in order to reflect on their experience. Some experienced effects of catharsis when they shared such feelings, and the resulting reflection brought about a shared emphasis on their mutual emotions. Participants who could not develop relationships with their colleagues or who did not have colleagues relied on senior and teaching doctors of similar ages. These participants developed similar relationships to those that others developed with their inner group.

During this organisational socialisation as a doctor, relationships with this inner group of colleagues or close supervising doctors brought out a range of responses which had both positive and negative effects on their adaptation in the hospital (table 3).

\section{Professional socialisation}

The four patterns of professional socialisation that we identified differed with respect to three themes: specialty area, self-learning style and organisational socialisation (table 4).

\section{Pattern 1: sophisticated balance between LPP and individual} learning style

Participants exhibiting this pattern established their professional image in the early stages and seriously considered themselves doctors and handled tasks smoothly by working in an organisation that matched their professional image.

Those who struggled to be a doctor that matched the image required by their hospital sometimes created new ways to solve this problem by involving other staff. The participants, who had no obligation to help, supported their hospital and staff because they felt a belonging to and professional identity with the hospital. These behaviours of the participants are concordant with the model of a reflective practitioner in an organisation. Through the reflection, participants were able to voluntarily commit to education, partnership, leadership and administration work as a doctor, which gave them increasing opportunities to train residents and to work with various healthcare professionals.

Participants with this pattern initiated LPP smoothly in the organisation and identified their own professional image within 2 years after graduation because they had a role model in the training hospitals. They subsequently proceeded to professional socialisation as a part of continuous organisational socialisation.

Pattern 2: focused more on their own professional image than LPP in the hospital

Participants with this pattern generated their professional image or learning style in their own way. Based on this, they clarified their own values and roles in practice. When they were junior residents, for example, when the participants' professional image was clearer, they could actively participate in the training hospital and develop their own goals. They had opportunities to transform their learning style by following their role models' advice.

In addition, they experienced transformative learning when they struggled to adapt to their changing life cycle and new environment, which they had never experienced previously. Through their experience, they developed the ability to reflect on their learning style and role as a doctor and look back on themselves from a broad perspective. 
Table 3 Emergent themes and professional identity formation based on interviews about realisation as a doctor and organisational socialisation

\begin{tabular}{|c|c|c|}
\hline Theme & $\begin{array}{l}\text { Professional identity } \\
\text { formation }\end{array}$ & Example quotes \\
\hline \multirow[t]{2}{*}{$\begin{array}{l}\text { Realisation as a } \\
\text { doctor }\end{array}$} & \multirow[t]{2}{*}{$\begin{array}{l}\text { Started to consider doctors' } \\
\text { image }\end{array}$} & $\begin{array}{l}\text { Doctor 2: 'I was not very interested in any of the medical departments. I } \\
\text { was told to go to the community clinic where a family physician worked, } \\
\text { (and once there) I found I wanted to be like a medical doctor I met there. } \\
\text { For the first time, my image of the future became vivid. Since then, I have } \\
\text { continued to strongly want to become a family physician.' }\end{array}$ \\
\hline & & $\begin{array}{l}\text { Doctor 13: '(What was particularly striking was) what patients told me } \\
\text { during home visits. 'I understand that medical doctors want to specialize } \\
\text { in a particular area, and rise in the ranks. That's good. However, as they } \\
\text { rise to greatness, they gradually stop listening to us. I want you to be a } \\
\text { doctor closer to patients.' This is what one patient told me.' }\end{array}$ \\
\hline \multirow{5}{*}{$\begin{array}{l}\text { Organisational } \\
\text { socialisation }\end{array}$} & \multirow{2}{*}{$\begin{array}{l}\text { Started organisational } \\
\text { socialisation in hospitals }\end{array}$} & $\begin{array}{l}\text { Doctor 5: 'Why do I need to come into the clinic on holidays? ....My } \\
\text { superior told me that it was to see patients once daily, without fail. I just } \\
\text { answered 'Yes'.' }\end{array}$ \\
\hline & & $\begin{array}{l}\text { Doctor 19: 'Including chores,...I stayed up until late at night, together } \\
\text { with doctors in the lowest position....I did what persons in the lowest } \\
\text { position should do in the manner appropriate for those in the lowest } \\
\text { position.' }\end{array}$ \\
\hline & Compared others & $\begin{array}{l}\text { Doctor } 1: \text { 'I cared so much about what other people thought of me, } \\
\text { compared to my other colleagues. I felt something like an inferiority } \\
\text { complex.' }\end{array}$ \\
\hline & Connected with colleagues & $\begin{array}{l}\text { Doctor 3: 'When I talked about my failures, it actually reduced the burden } \\
\text { on my heart. We shared our experiences and did not criticize each other. } \\
\text { We worked under these circumstances, which contributed to our mental } \\
\text { stability because we felt that we received training in a safe and secure } \\
\text { environment, and did not need to hold things inside.' }\end{array}$ \\
\hline & $\begin{array}{l}\text { Connected with senior } \\
\text { doctors }\end{array}$ & $\begin{array}{l}\text { Doctor 8: 'There were many doctors responsible for supervising and } \\
\text { instructing residents. So I learned a lot and saw a lot, and whenever I } \\
\text { faced difficulties, even small challenges, I was taught and instructed.... } \\
\text { They always kept me in their mind ...they were always kind to me, and } \\
\text { they let me join their group.' }\end{array}$ \\
\hline
\end{tabular}

Even those who were able to create a professional image in the early stages of their training could transform their values if they came into contact with others with better values. In this way, they confirmed their own role by creating relationships with others and exploring meaningful perspectives for their own growth.
Pattern 3: clarified their own vague professional image by referring to role models or the organisations to which they belonged (specific persons or organisations)

Participants with this pattern had not established their own professional image as a doctor when they were medical students and trainees. Therefore, they adapted their learning styles to those accepted by the organisation 
Table 4 Emergent themes and professional identity formation based on interviews about 4 patterns of professional socialisation

\begin{tabular}{l} 
Theme \\
\hline Professional socialisation \\
Pattern 1: Sophisticated \\
balance between LPP \\
and individual learning \\
style
\end{tabular}
Struggled to be a
doctor

\section{Professional identity} formation

Established their professional image in the early stages

doctor

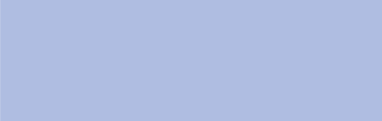

Pattern 2: Focused more on their own professional image than LPP in the hospital

\section{Example quotes}

Doctor 3: 'I was able to commit myself to (the department's) philosophy and vision ....my boss sincerely endeavored to teach it.'

Doctor 20: 'I was able to be engaged in diagnosis through treatment ...I wanted to involve myself in actual clinical practice as a teaching doctor, which was my desire .... I think that this area will grow in the future.'

Doctor 3: '(In the early phase of my senior residency) I established good relationships with junior residents working in the same hospital. I noticed that the junior residents were extremely unknowledgeable, or not adequately taught, as I had expected, but were forced to survive under these circumstances anyway. Therefore, I supported their survival, even though I was not asked to do so by anyone.'

Doctor 16: '(After returning to the hospital) I invited first-year and secondyear residents from the primary care course to attend the study group meetings, where I gave talks to invoke discussion amongst them. In addition, I thought that such an organization should exist for residents, and three of us who started our residencies at the same time collaborated to create a new organization for residents.'

Committed to the work Doctor 16: '(When training residents), I realized that individuals differ as non-clinicians in their speed of learning, ....When a resident could not achieve a predetermined target, I tried to intervene in his/her training as soon as I noticed that the resident was failing to achieve the target and that it was becoming a problem.'

Clarified their own values and roles in practice

Transformed their learning style

Struggled to adapt to the life of doctors
Doctor 2: 'In the Department of General Internal Medicine, we have to address issues for which there are no solutions, and we need to handle individuality very seriously; that is, we have to think about how we approach individual patients. I thought that these things were very challenging.'

Doctor 6: 'I have thought that palliative care was a good fit for me since junior residency... I wanted to concentrate on a specialized area so as to actually experience self-efficacy because I had not developed self-efficacy as a family physician during my senior residency.'

Doctor 6: 'I knew the scope of learning in the area of family medicine and identified what I had to learn within that scope from my rotations. I showed my goals to my teaching doctor (Oben) and told my Oben, 'this is what I want to learn'. That is what I did. I continued in this way for a while; that is, setting goals and trying to achieve them.'

Doctor 7: 'I learned almost everything by asking the instructing doctors to teach me from scratch. And when I was told to read some text after asking a question, I always read it prior to starting work. That was my learning style.'

Doctor 2: 'I had to manage raising a child and doing housekeeping with working in a well-balanced manner. This balancing act helped me to work efficiently in clinical settings. I thought that the two were somehow interlinked. Thus, I successfully balanced the two and I think I enjoyed both of them.'

Doctor 6: 'After I started a doctoral course, I was not engaged in clinical practice at all. This was not good for me and I found that the lack of engagement in clinical practice did not increase my self-efficacy. Therefore, I want a good balance between research and clinical practice.' 
Table 4 Continued

\section{Theme}

Pattern 3: Clarified their own vague professional image by referring to role models or the organisations to which they belonged (specific persons or organisations)

Identified role as a generalist

Pattern 4 : Professional image was unclear formation

Identified role as a specialist set for professional
Professional identity

\section{Example quotes}

Doctor 18: 'I actually knew nothing about emergency care in the Department of Gynecology; I was not good with women and I didn't know anything about gynecology, so I thought that it would be good for me to work in that department for about one year. The doctor told me about lots of things that had occurred in the past. What the doctor told me was more than what I learned from textbooks, and to be honest, I did not need to find the time to read books. I did not 'study' to become a specialist doctor.'

Doctor 19: 'After surgery, we had a meeting for about 2 hours late at night ...reading images on a screen, and in this way, I increased my knowledge about various diseases. (At the training hospital) there were doctors specialized in the spinal cord. There, I learned about surgery of the spinal cord.'

Doctor 1: 'There are many cases of fever due to unknown causes, right?.. At present, I frequently come up with ideas to change my mood to a positive state. However, I did not do that when I was training. I don't think that I enjoyed my days very much.'

Doctor 11: 'Twelve years after graduation, I had finally become a doctor. I mean, after all, I had studied what I needed to study. Before that time, the only way to learn was to ask specialists.'

Waited out the period identity formation moratorium

Doctor 5: 'In the beginning, in my first year of being a doctor, I often questioned, 'why should I go to the hospital on holidays? I understood that I should go, but I would rather not go as much as possible...' Ultimately, I realized that I had acquired the ability to handle anything without thinking. (After completing my senior residency training), I very often tried to find an area that I was interested in. Consequently, for 6 months from the beginning of my seventh year, I worked at the Department of Internal Medicine of Metabolism as part of my rotations.'

Doctor 8: '(When I was a resident) I had no confidence and I therefore did not say or touch unnecessary things. As such, I was so passive and hesitant ....Even now, I think I still have such an attitude, although there is no definitive reason for this. However, something changed and happened, and I learned from it, which broadened my perspective. I became aware that other doctors were in trouble and that I had to learn more. I wanted to learn more with other doctors because I also did not know enough.'

Doctor 9: 'I didn't hold the perspective that 'I will learn in this department for the sake of my future.' So I only focused on the department that I was assigned to. I never thought that I enjoyed my job. Therefore, after qualifying as a doctor, I wondered if it was right. For me, it is significantly important to help somebody (as a doctor). I am very motivated by the fact that somebody needs me.'

Doctor 10: 'When teaching another senior resident, I felt, 'Oh, that resident improved a lot in a short time!' Upon reflection, I looked back on my own progress and realized how much his skills had improved. This triggered me to think about my own skills. ...I am not good at thinking about multiple things at the same time, even though this is frequently required of doctors. Therefore, I tried to train myself to think about multiple things simultaneously.'

Doctor 13: 'I noticed for the first time that my teaching doctor was surprised with me, which made me look back on what I had done over the past 2 years. That particular doctor told me over and over again, forcefully, that hospitals and comprehensive medical care services and the like are really necessary.... In the middle of my training as a senior resident, I returned to the hospital.'

LPP, legitimate peripheral participation. 
concerned. Through these adapted styles, they were able to become like their superior role models or establish a professional image that was as close as possible to the externally recognised professional image accepted within the organisation.

Several characteristics of this pattern differed between specialists and generalists. Even when specialists such as neurosurgeons or obstetrician-gynaecologists had not adequately established their own professional image while they were trainees, they stayed in these specialty departments and were eventually able to successfully establish their own individual learning styles and stably place themselves in strategic positions within the organisation. They could be distinguished from other specialists and were externally recognisable professionals. That is, they established their own professional image under the apprenticeship system embedded in the organisation and through experiential learning, which helped them build their own specialty. Their professional socialisation, therefore, occurred through their organisational socialisation.

In contrast, family physicians and emergency doctors are less defined by a particular procedural skill or role. They, therefore, struggled to adapt to organisational socialisation because their externally recognised professional belonging remained vague. In addition, the learning styles of family physicians and emergency doctors varied depending on the organisation, and it therefore took them longer to establish their own learning styles.

In this way, they experienced LPP in any organisation to which they were assigned. They experienced organisational socialisation at each of their training hospitals while they participated in clinical rotations, and made comparisons with their own professional image.

\section{Pattern 4: professional image was unclear}

To identify their ideal image of a doctor, participants with this pattern adapted to the ways accepted by their organisation for the fulfilment of duties, relied on recognition from others, and limited their activities to those required by the organisation. As a result, they failed to establish their own learning style at the beginning, and wanted teaching doctors to lead them, or to accumulate experience in areas in which they had not yet acquired experience. They were not confident as doctors and tended to confirm the validity of their decisions with staff who were widely trusted in the organisation. This demonstrates that doctors continue to explore their own professional image even after they become established doctors. As a result, they wanted a place of training where they could fill holes in their knowledge. Some doctors established their image as a doctor under the conditions provided to them, while others tried to find their personal identity through relationships with other doctors.

\section{DISCUSSION}

This study showed that, in the early stages of their socialisation process, doctors experienced not only realisation as doctors, but also organisational socialisation, in which they adapted to the hospital in which they underwent residency training. Subsequently, the doctors exhibited four patterns of professional socialisation that differed according to three themes: specialty area, self-learning style and organisational socialisation. Some doctors-even those who developed into established doctors-became lost in the professional socialisation process. Our study uniquely demonstrates the chronological patterns of the professional socialisation of Japanese doctors including their hospital training, using educational theories.

Our finding that there are common factors between the realisation and organisational socialisation of doctors is in agreement with the institutional theory. ${ }^{29}$ Medical universities are predetermined to train doctors using both intended and hidden curriculum. Several studies have indicated that medical students in a university's medical school are ideologically socialised as clinicians with respect to their vision and experience. ${ }^{30}$ In clinical training for medical students, realisation as a doctor is interpreted as anticipatory socialisation. ${ }^{31}$ This realisation has been suggested to begin when a person starts to realistically review his/her career, while focusing on their profession, before he/she participates in a specific organisation. In contrast, when students become junior residents, they fulfil roles required by the organisation, such as a hospital, to secure progress in their organisational socialisation. ${ }^{32}{ }^{33}$ During this period, however, the students' skills have not reached a high level and they therefore contribute to their organisations by fulfilling the various roles required by the organisation. Through these processes, they become adapted to the hospital as established doctors and achieve socialisation.

Professional organisations are affected bya professional image 34,which is composed of the perspectives of outsiders and self-recognition of one'sown competency. ${ }^{34}$ Doctors struggle to develop an external person a consistent with the expectations of their surroundings. In patterns 3 and 4 , in which the professional image is vague or unclear and is not recognised by the organisation, the participants temporarily experienced a 'pretend' socialisationin terms of the culture of their training hospital and their role in it. However,their experience differed from that of the ideal identity in their specialty area, and they, therefore, required role models as external examples. Accordingly, they had to accumulate experience in areas in which they were not competent to establish an image as a doctor that matched the professional image (eg, family physician or emergency physician). In contrast,specialists, for whom the professional image is externally established (eg, gastroenterologists, obstetrician-gynecologists and neurosurgeons) began practising LPP in the organisation once they had chosen their specialisation. They were subsequently integrated as members of the organisation while developing their professional identity as specialisation once they had chosen their specialisation. They were subsequently integrated as members of the organisation while developing their professional identity as specialists. 
In pattern 1, medical doctors who wanted to become family physicians continued to engage in LPP in the organisation after they had established a professional identity and externally recognised persona as a family physician within the hospital. These experiences can promote determination as a doctor through threshold concepts (TCs). ${ }^{35}$ TCs, which are usually transformative, integrative, irreversible, bounded and often troublesome, are key to formalising a professional identity in a vague professional image. In particular, TCs often arise when doctors engage in the reflective practice of playing the multiple ambiguous roles expected of them within their organisation, based on the sense of noblesse oblige- the notion that doctors should use their social position to help others. ${ }^{36}$

In this way, training at an organisation which provides a professional image that is consistent with that of the trainee enables LPP and helps the trainee to develop their professional identity. We found, however, that when professional images differed, some trainees distanced themselves or struggled to become a member of the organisation. These series of processes for building the professional identity and socialisation of doctors may enable medical teachers or residency programme directors to provide career support to medical students or junior residents.

This study had the following limitations: we only interviewed 21 participants in Japan, of whom many were family physicians and only a small number were specialists; many of the participants had advanced their careers as doctors relatively satisfactorily; only two doctors had experienced pregnancy and childbirth; and none became doctors after 2010, when the Japanese government revised the rules for clinical training for doctors. The findings may be subject to a degree of sample selection and response bias in that some participants were known to the interviewers and volunteered to participate. The study results should be interpreted with these limitations in mind, along with the fact that the findings reflect the perspectives of family physicians and Japanese culture in the above-mentioned context.

Allowing for these limitations, this study clarified the process of socialisation of medical doctors. This clarification was based on detailed interviews which focused on the continuity of the participants' careers as doctors from a family physician perspective, as compared with the perspectives of other specialties. Nevertheless, doctors in other specialties may also find our results useful given that very few studies of this type have been conducted. Our findings have the potential to substantially impact the development of future medical school curricula. For example, in career education, the patterns of socialisation of medical doctors may provide trainee doctors with an idea of career milestones and ways to choose a career. In addition, these findings will act as a guide for individual doctors considering their career plans, and may help organisations which consider doctors' career plans by showing the potential need to reflect on the four patterns of self-learning style and specialty areas at milestones. Our future plans to evaluate medical professional identity formation include cross-sectional studies or cohort studies to check the robustness of our present results at larger scale. ${ }^{37}$

\section{CONCLUSION}

This study suggests that anticipatory socialisation and organisational socialisation of medical doctors may be similarly achieved, and that professional socialisation may be affected by the extent to which medical doctors establish their professional identity; the extent to which their professional image matches that of the organisation; and the extent to which the professional image is externally recognised. Our study uncovers the process by which doctors are socialised, and is expected to offer insight to various stakeholders engaged in medical education.

\section{Author affiliations}

${ }^{1}$ Medical Education Center, Keio University, Shinjuku, Tokyo, Japan

${ }^{2}$ Faculty of Medicine, University of Tsukuba, Tsukuba, Ibaraki, Japan

${ }^{3}$ Department of General Medicine and Primary Care, Faculty of Medicine, University of Tsukuba, Tsukuba, Ibaraki, Japan

${ }^{4}$ Division of Clinical Medicine, Faculty of Medicine, University of Tsukuba, Tsukuba, Ibaraki, Japan

Contributors JHar, S0 and JHam were involved in the conception and design of this study, carried out all qualitative enquiries, analysed the data and wrote the paper.

Funding This study received education/research funds from the Department of Primary Care and Medical Education, University of Tsukuba, and was supported by Ministry of Education, Culture, Sports, Science and Technology, New Paradigms Establishing Centers for Fostering Medical Researchers of the Future; and Doctors for Communities (DOCS) - Fostering Research-Minded General Physicians.

\section{Competing interests None declared.}

Patient and public involvement Patients and/or the public were not involved in the design, or conduct, or reporting, or dissemination plans of this research.

\section{Patient consent for publication Not required.}

Ethics approval This study was conducted with prior approval from the Ethics Committee of the Faculty of Medicine, University of Tsukuba (No.1001).

Provenance and peer review Not commissioned; externally peer reviewed. Data availability statement No data are available.

Open access This is an open access article distributed in accordance with the Creative Commons Attribution Non Commercial (CC BY-NC 4.0) license, which permits others to distribute, remix, adapt, build upon this work non-commercially, and license their derivative works on different terms, provided the original work is properly cited, appropriate credit is given, any changes made indicated, and the use is non-commercial. See: http://creativecommons.org/licenses/by-nc/4.0/.

\section{ORCID iDs}

Junji Haruta http://orcid.org/0000-0003-4176-7665

Jun Hamano http://orcid.org/0000-0003-0304-9881

\section{REFERENCES}

1 Cruess RL, Cruess SR, Boudreau JD, et al. A schematic representation of the professional identity formation and socialization of medical students and residents: a guide for medical educators. Acad Med 2015;90:718-25.

2 Hershey JL. The lived experience of becoming a professional nurse for associate degree nursing graduates: a phenomenological study (ProQuest Dissertations and Theses), 2007. 
3 Cruess RL, Cruess SR, Boudreau JD, et al. Reframing medical education to support professional identity formation. Acad Med 2014;89:1446-51.

4 Suter E, Arndt J, Arthur N, et al. Role understanding and effective communication as core competencies for collaborative practice. $J$ Interprof Care 2009;23:41-51.

5 Finn G, Garner J, Sawdon M. 'You're judged all the time!' students' views on professionalism: a multicentre study. Med Educ 2010;44:814-25.

6 Cruess RL, Cruess SR, Boudreau JD, et al. A schematic representation of the professional identity formation and socialization of medical students and residents. Academic Medicine 2015;90:718-25.

7 Ashforth BE, Sluss DM, Harrison SH. Socialization in Organizational Contexts. In: Ford G, ed. International review of industrial and organizational psychology. John Wiley \& Sons Ltd, 2007: 1-70.

8 Bauer TN, Bodner T, Erdogan B, et al. Newcomer adjustment during organizational socialization: a meta-analytic review of antecedents, outcomes, and methods. J Appl Psychol 2007;92:707-21.

9 Lave J, Wenger E. Legitimate Peripheral Participation in Communities of Practice. In: Clarke J, Hanson A, Roger Harrison FR, eds. Supporting lifelong learning. Routledge, 2001: 121-36.

10 Cruess RL, Cruess SR, Steinert Y. Amending Miller's Pyramid to Include Professional Identity Formation. Acad Med 2016;9:180-5.

11 Goldie J. The formation of professional identity in medical students: considerations for educators. Med Teach 2012;34:e641-8.

12 Birden H, Glass N, Wilson I, et al. Teaching professionalism in medical education: a best evidence medical education (BEME) systematic review. BEME guide No. 25. Med Teach 2013;35:e1252-66.

13 Birden H, Glass N, Wilson I, et al. Defining professionalism in medical education: a systematic review. Med Teach 2014;36:47-61.

14 Hilton S, Southgate L. Professionalism in medical education. Teach Teach Educ 2007;23:265-79.

15 Rodríguez C, Pawlikowska T, Schweyer F-X, et al. Family physicians' professional identity formation: a study protocol to explore impression management processes in institutional academic contexts. BMC Med Educ 2014;14:184.

16 Stein HF. Family medicine's identity: being generalists in a specialist culture? Ann Fam Med 2006;4:455-9.

17 Raghavendran S, Inbaraj LR. Do family physicians suffer an identity crisis? A perspective of family physicians in Bangalore City. J Family Med Prim Care 2018;7:1274-8.

18 Riessman CK. Narrative methods for the Human Sciences. In: Riessman CK, ed. Narrative methods for the human sciences. SAGE Publications, 2008: 1-250.

19 Merriam SB. Qualitative Research: A Guide to Design and Implementation. In: The JosseyBass higher and adult education series. 3rd ed. Jossey-Bass, 2009: 1-304.
20 Wong A, Trollope-Kumar K. Reflections: an inquiry into medical students' professional identity formation. Med Educ 2014;48:489-501.

21 Monrouxe LV. Negotiating professional identities: dominant and contesting narratives in medical students' longitudinal audio diaries, 2009.

22 OECD. Doctors (indicator) [Internet], 2020. Available: https://data. oecd.org/healthres/doctors.htm\#indicator-chart [Accessed $1 \mathrm{Apr}$ 2020].

23 OECD Data. Hospital Beds - OECD Data [Internet]. OECD, 2018. Available: http://www.oecd.org/els/waiting-times-for-electivesurgery-what-works-9789264179080-en.htm [Accessed 1 Apr 2020].

24 File|Browse Statistics. Portal Site of Official Statistics of Japan [Internet]. Available: https://www.e-stat.go.jp/en/stat-search/files? page $=1$ \&toukei $=00450021$ \&tstat $=000001030908$ [Accessed 1 Apr 2020].

25 Takamura A. The present circumstance of primary care in Japan. Res Artic Open Access Qual Prim Care 2015;23:262-6.

26 Japan Primary Care Association. The number of certified family physicians (Japanese)- [Internet]. Available: https://www.primarycare.or.jp/nintei_fp/fp_list.php [Accessed 1 Apr 2020].

27 Wilson I, Cowin LS, Johnson M, et al. Professional identity in medical students: pedagogical challenges to medical education. Teach Learn Med 2013;25:369-73.

28 Gregg GS. The raw and the Bland: a structural model of narrative identity. in: identity and story: creating self in narrative. Washington: American Psychological Association, 2006: 63-87.

29 Glynn MA, Abzug R. Instituionalizing identity: symolic isomorphism and organizational names. Acad Manag J 2002;45:267-80.

30 Hafler JP, Ownby AR, Thompson BM, et al. Decoding the learning environment of medical education: a hidden curriculum perspective for faculty development. Acad Med 2011;86:440-4.

31 Cruess RL, Cruess SR, Boudreau JD, et al. Socialization of medical students and. Acad Med 2015;90:718-25.

32 Byszewski A, Gill JS, Lochnan H. Socialization to professionalism in medical schools: a Canadian experience. BMC Med Educ 2015;15:204.

33 Pitts R. An exploratory case study: effects of a physician organizational socialization (enculturation) program. Perm J 2009;13:31-6.

34 Morgan L, Roberts LM. Changing Faces : Professional Image Changing Construction in Diverse Settings Organizational. Management 2011;30:685-711.

35 Neve H, Wearn A, Collett T. What are threshold concepts and how can they inform medical education? Med Teach 2016;38:850-3.

36 Bhat C, Burm S, Mohan T, et al. What trainees grapple with: a study of threshold concepts on the medicine ward. Med Educ 2018:52:620-31.

37 Tagawa M. Development of a scale to evaluate medical professional identity formation. BMC Med Educ 2019;19:63. 